\title{
ПРОБЛЕМНЫЕ ВОПРОСЫ КВАЛИФИКАЦИИ МОШЕННИЧЕСТВА В СФЕРЕ БИРЖЕВОГО ОБОРОТА ЦЕННЫХ БУМАГ ПО ЗАКОНОДАТЕЛЬСТВУ ГЕРМАНИИ, ИСПАНИИ, ИТАЛИИ, ФРАНЦИИ И ЧЕШСКОЙ РЕСПУБЛИКИ
}

Аннотация. Предметом исследования является рассмотрение особенностей квалификации мотенничества в сфрере биржевого оборота ценных бумаг по национальному законодательству Германии, Испании, Италии, Франциии и Чешской Республики с точки зрения конфликта национальных и международных юрисдикций, а также анализ общих для этих стран проблем определения моченнической деятельности. Особенное внимание при этом уделено вопросу коллизий при выборе юрисдикиий и мошенничеству, основанном на разногласиях национальных юрисдикиий как основному источнику разногласий при квалификации мошенничества на рынках ценных бумаг. В проведенном анализе эмпирическими методами исследованы современные особенности развития национальных и международных фондовых рынков, определяющие наиболее характерные особенности мошеннической деятельности в сфере оборота ценнных бумаг в Германии, Испании, Италии, Франџии и Чешской Республики. В результате выделены общие подходы в квалификачии мошенничества с цеенными бумагами (материальность, преступный умысел, манипуляции с иенными бумагами), а также проблемы, которые на данный момент рассматриваются в судах исследуемых стран, в том числе в судах высшей инстанции. Проблемными вопросами являются определение юрисдикиии заключаемой сделки, пересмотр юрисдикиии в случае подозрения в мошенничестве и вопрос определения понятия «ценные бумаги». Научная новизна работы определяется отсутствием определения отдельных аспектов квалификации мошенничества на рынке ценных бумаг в законодательствах Германии, Испании, Италии, Франции и Чешской Республики, несмотря на развитый фондовый рынок этих стран и регулирование данного вопроса международными институцчиями (прежде всего, институцииями ЕC). Опыт решения этих проблем, прежде всего при конфликте юрисдикиий, имеет важное теоретическое и практическое значение, особенно для российской юридической научной мысли в свете интенсификации международных судебных процессов, затрагиваюших экономические преступления.

Ключевые слова: Квалификачия, моченничество, рынок иенных бумаг, фондовый рынок, Германия, Франция, Италия, Испания, Чехия, юрисдикиия.

Abstract: The subject of the research is to examine the features of qualifications on the national legislation of Germany, Spain, Italy, France and the Czech Republic in terms of conflict of national and international jurisdictions, as well as the analysis of common problems for these countries the definition of fraudulent activity. Particular attention is paid to the issue of collisions of jurisdiction choosing and fraud, based on differences of national jurisdictions as the main source of differences in the classification of fraud in the securities markets. To analyze empirically researched modern features of the development of national and international stock markets, the most defining characteristics of fraudulent activity in the field of securities turnover in Germany, Spain, Italy, France and the Czech Republic. As a result, a common approach highlighted in qualifying securities fraud 
(materiality, criminal intent, manipulation of securities), as well as problems that are currently dealt with in the courts of the countries studied, including in higher courts. Problematic issues are to determine the jurisdiction of concluded transaction, the revision of the jurisdiction in case of suspicion of fraud and the question of the definition of "securities". The scientific novelty of the work is determined by the lack of a definition of certain aspects of qualification fraud in the securities market in the legislation of Germany, Spain, Italy, France and the Czech Republic, despite the development of the stock market in these countries and the regulation of matters of international institutions (primarily EU institutions). Experience of resolving these problems, especially in a conflict of jurisdictions, has important theoretical and practical significance, especially for the Russian legal thought in the context of the intensification of international trials involving economic crimes. Keywords: Fraudulence, Bond market, Stock market, Germany, France, Italy, Spain, Czech Republic, Jurisdiction, Qualification.

овременные процессы развития на мировых рынках ценных бумаг отмечаются динамичностью, внедрением инновационных технологий и финансового инжиниринга, увеличением объемов обслуживания капитала на фондовых рынках, их существенным ростом, процессами объединения и кооперации в зависимости от региона или от сферы деятельности. В то же время, фондовый рынок каждой страны не полностью вовлечен в мировые финансово-инвестиционные процессы, что приводит, зачастую, к правовым коллизиям, основанным на различиях законодательств, чем с успехом пользуются мошенники. Поэтому с особой актуальностью возникают проблемы поиска эффективных форм, методов и инструментов препятствования мошенничеству на национальных рынках ценных бумаг, особенно при вовлечении в фондовую торговлю международных клиентов и посредников. Проблемы, характерные для наиболее развитых стран Евросоюза, особенности оборота ценных бумаг и международный характер торговли, технически воплощенный в виртуальном пространстве, делает особенно актуальным изучение проблем, с которыми сталкиваются эти государства при учете международных и национальных юрисдикций и особенностей их применения. Именно проблемы квалификации мо- шенничества в законодательной практике Германии, Испании, Италии, Франции и Чешской Республики довольно полно характеризируют проблемы европейского рынка ценных бумаг в целом и международной торговли в особенности.

Тенденции и динамизм финансово-инвестиционных отношений в мире, их сложность и многовекторность, требуют гибкой адаптации к внешним угрозам и возможностям современной мировой финансовой системы на законодательном уровне. Глобализация финансово-инвестиционных отношений повлияла на то, что проблемы конкретной страны теперь взаимосвязаны со многими другими странами. Часто эти проблемы, прямо, косвенно или фрагментарно, а иногда и структурно влияют на все страны мира, которые имеют значимые внешнеэкономические торговые и финансовые связи.

Проявлением вышеупомянутого динамизма в мире является специфика проблем фондового рынка Европы, которая требует стратегического плана законодательных реформ, тактических инструментов их реализации, существенных внутренних ресурсов и переосмысления парадигмы взаимозависимости стран внутри ЕС с глобальным восприятием нового развития. Централизация органов власти Евросоюза, унификация и расширение перечня социально-экономи- 
ческих стандартов существенно влияет на национальные рынки на законодательном уровне и регламентирует функционирование национальных экономик, зачастую игнорируя национальную специфику [1].

Это значит, что глобализация, международная конкуренция за рынки сбыта товаров и услуг, политическая, финансово-инвестиционная и экономическая нестабильность в мире в значительной степени трансформирует международный рынок ценных бумаг, придает ему динамичный и непредсказуемый характер. Функционирование современных фондовых бирж и их инфраструктуры нацелены на прозрачность, открытость, глобальность, унифицированность стандартов и правил работы. Все это в целом способствует накоплению юридических коллизий.

Отметим, что глобализированность мировой экономики и открытость к инвестированию на большинстве фондовых бирж мира ведет к резкому повышению рисков мошенничества на мировых рынках ценных бумаг.

Также мировой проблемой является искажение конкуренции с использованием современными бизнес-структурами оффшоров, вследствие чего происходит «тенизация» капитала, его дефицит или избыток в определенных регионах мира, что существенно влияет в дальнейшем на уровень мошеннических сделок на фондовом рынке. Слишком часто мошенничество сопряжено со значительными объемами теневых капиталов, особенно в наличной форме даже вопреки запретам на приобретение значительных объемов ценных бумаг за наличность. Также мошенники часто используют теневые доходы для биржевых афер, что также создает проблемы для международных организаций по борьбе с отмыванием денег. В связи с этим на международном уровне давно ведутся дискуссии о целесообразности унифицировать и принять новые правила игры для бизнеса, снизив привлекательность «офшоризации» в мире, что требует соответственной гармонизации и изменения на законодательном уровне [2].

Достаточно опасной является также тенденция, связанная с концентрацией капиталов и ростом числа транснациональных корпораций и банков (ТНК и ТНБ). Национальное регулирование таких структур становится почти невозможным, а действенных инструментов на международном уровне по уменьшению их влияния на дестабилизацию мировой экономики не существует. Все это также несет дополнительные риски для фондовых бирж мира. Учитывая это, существует системное явление укрупнения и слияния фондовых бирж на национальном и международном уровнях. Интернационализация институтов фондового рынка - это логичный ответ на продолжающуюся в течение нескольких десятилетий интернационализацию корпоративного сектора. Таким образом, резюмируя краткий обзор новейших тенденций на фондовом рынке Европы и мира, можно определить важнейшие из них:

- секьюритизация (securitisation) финансовых операций с акцентом на развитие корпоративных финансовых инструментов (прежде всего акций и их производных)

- активизация участия европейских финансовых институтов в глобальных операциях (в значительной степени под влиянием американских конкурентов);

- интеграция фондового рынка стран Европы (не только в пределах ЕС) и, как результат, межгосударственная консолидация институтов инфраструктуры фондового рынка;

- сегментация европейского фондового рынка, которая усиливается за счет появления большого количества новых национальных рынков, которые, стремясь интегрироваться в общеевро- 
пейское экономическое пространство, на данном этапе вынуждены решать проблемы своего становления, поэтому и рискуют значительно отстать (количественно и качественно) от группы стран-лидеров [2].

С 2009 года было введена директива ЕС «О рынках финансовых инструментов», согласно которой финансовый рынок стран Европейского содружества работает по новым правилам, которыми отменен ряд операций с финансовыми активами. Все сделки с введением этой директивы на едином европейском рынке регистрирует Европейский комитет регуляторов фондовых рынков (CESR). Зарегистрированные в одном государстве ЕС финансовые компании теперь могут непосредственно действовать в любой стране ЕС без создания филиалов и представительств. Кроме того, было снято ограничение на операции с деривативами во Франции, Испании и Италии, тогда как ранее местные торговые площадки имели монопольное право на организацию таких торгов. Это привело к значительному усилению конкуренции между финансовыми посредниками и организаторами торговли. Если раньше у фондовых бирж не было конкурентов, то теперь торговые площадки могут создавать инвестиционные банки, что в значительной мере увеличивает поле деятельности для финансовых мошенников [3].

В целом, для стран-членов ЕС обязательной для исполнения является имплементированная система директив ЕС, которая регулирует оборот ценных бумаг. В нее входит целый ряд директив с учетами и дополнениями [4-21].

Главной проблемой для национальных юрисдикций, таким образом, является вопрос соотношения национальных, союзных (для всего Европейского Союза) и международных правоприменений. Именно в этой сфере фиксируется значительное количество фактов мошенничества или злоупотреблений, однако эта область остается до сих пор мало изученной. Среди причин отсутствия внимания к этим вопросам мы видим, в частности, следующие.

Во-первых, материальное право государств с наиболее развитыми фондовыми рынками (Германия, Франция, Италия), которое определяет права и обязанности сторон операций с ценными бумагами, настолько подобны в своих основных нормативных и правоприменительных механизмах, что особой разницы в том, какое конкретно право следует признать приемлемым, вроде нет [22].

Во-вторых, коллизионные нормы права подавляющего большинства государств мира признают принцип автономии воли сторон и осуществляют на его основе выбор права (достаточно сложно представить себе многомиллионную операцию на международном рынке ценных бумаг, стороны которой просто «забыли» внести в договор оговорки о применимом праве), а если такой выбор все же не был сделан, поиск правопорядка, с которым операция имеет наиболее тесную связь, также не связан с особыми трудностями.

В-третьих, купля-продажа ценных бумаг на организованном рынке происходит, как правило, на основе стандартизированных договорных форм - с использованием типовых договоров (master agreements) или общих условий договоров такого рода, выработанных практикой международного фондового рынка, предусматривающих, в частности, и выбор права юрисдикции с развитым законодательством и опытом рассмотрения дел в сфере международных финансовых операций (как правило, права Англии или штата Нью-Йорк для международных бирж) [22].

Более острым традиционно считается вопрос юрисдикционной компетенции. Как отмечает немецкий исследователь Г. 
Шустер, вопрос определения применимого договорного права в конкретной операции часто трансформируется в вопрос о возможности экстерриториального осуществления юрисдикции в отношении международных операций с ценными бумагами [23]. Однако коллизионные аспекты осуществления операций с ценными бумагами относительно квалификации мошеннических действий заслуживают отдельного исследования.

Одним из основных коллизионных институтов в международном частном праве является принцип автономии воли сторон, который «является органическим объединением двух начал - коллизионного (по назначению) и принципа свободы договора (по способу реализации)» [24]. Однако, термин «автономия воли» не означает, что участники правоотношений имеют неограниченные абсолютные права. Наоборот, это условное понятие, поскольку государство оставляет за собой право самостоятельно устанавливать законодательными актами случаи, в которых сторонам может предоставляться возможность выбора закона, который применяется [24].

Концепция «императивных норм» признается одним из ограничений такого волеизъявления, что объективно выражается в форме оговорки о применимом праве. По мнению Г. Шустера, она «является достаточно сложной конструкцией, которая объединяет в себе элементы публично-правового регулирования, концепцию «тесной связи» (права, свойственного договору) и концепцию «обхода закона», а также американские коллизионные теории» [23]. Ее суть заключается в наличии в рамках определенного внутригосударственного правопорядка группы норм, действие которых не может быть устранено сторонами выбором применимого права, если операция и порожденное ею гражданское правоотношение всеми своими элементами имеют объективную связь только с этим правопорядком. Кроме того, в теории международного частного права выделяется и специальная категория «оверимперативних норм», которые являются составной частью законодательства государства, имеют тесную связь с гражданскими правоотношениями, являются предметом рассмотрения суда, и которые при определенных условиях подлежат применению per curiam, независимо от выбора сторонами применимого права. Такие правила применимы, прежде всего, при подозрении сторон в мошенничестве, особенно в Германии и Франции.

Таким образом, выбор, сделанный сторонами, в ряде случаев может не признаваться судом. Правовое регулирование ценных бумаг являет особой отрасль права, где частноправовые элементы неразрывно связаны с публично-правовыми. Упоминавшаяся выше категория «оверимперативных норм» связана с понятием «публичного интереса» [24], который в случае с операциями на фондовом рынке может включать стандарты поведения участников рынка ценных бумаг (включая нормы о запрете инсайдерской торговли) и принципы защиты прав инвесторов (например, в Чехии, Италии, Испании приоритетно декларируется защита внутреннего инвестора, что, к сожалению, является основой для многочисленных мошеннических схем, в частности отмывания денег с помощью миноритарных акционеров) [25].

В ряде стран (Бельгия, Франция, Германия, Италия, Норвегия, Испания, Великобритания, Чехия в том числе) осуществление операций с определенными категориями ценных бумаг связано с выполнением формальных действий (например, получением специального разрешения регуляторного органа) или вообще может находиться под запретом (например, отчуждение акций ключевых промышленных предприятий иностранцам), и такие нормативные предпи- 
сания, скорее всего, будут признаны судом императивными нормами. Непризнание судом избранного сторонами применимого права, вполне вероятно, будет следствием обнаруженного мошенничества с ценными бумагами. Так, суд, очевидно, откажет в признании недобросовестного выбора права, сделанного сторонами договора купли-продажи ценных бумаг на предъявителя, оборот которых был остановлен на основании Конвенции Совета Европы 1980 года о прекращении обращения ценных бумаг на предъявителя, находящихся в международном обороте [26]. Данная Конвенция направлена на защиту владельцев ценных бумаг, которые характеризуются повышенной оборотоспособностью, и предусматривает возможность прекращения обращения ценных бумаг на предъявителя, если они выбыли из владения лица в результате потери, кражи, неправомерного обмена, мошенничества или иного противоправного воздействия. Если профессиональный посредник осуществляет поставку ценной бумаги, по которой на дату поставки оглашена международная публикация о прекращении ее обращения, то он должен поставить покупателю другую ценную бумагу такой же категории вместо бумаги, обращение которой приостановлено. При этом данное положение должно применяться без ущерба для других прав покупателя, предоставляемых ему применимым правом (ст. 15 Конвенции). Попытка сторон договора обойти применения данной Конвенции путем выбора права государства, которое не принимает в ней участия, может быть признана судом злоупотреблением автономией воли.

Однако существует ряд случаев в сфере обращения ценных бумаг, когда суды все же склонны применять императивные нормы права другого государства, особенно при подозрении в мошенничестве. Наиболее распространенным правилом является об- ращение к правилам при спекулятивных операциях относительно деривативов мошенничеством могут классифицировать операции спекулятивного характера в целом ряде национальных юрисдикций. Например, в ряде юрисдикций (Италия, Испания, Чехия) операции с фьючерсами могут быть признаны не подлежащими принудительному исполнению в судебном порядке, если они имеют исключительно спекулятивный характер, а не направлены на страхование рисков, или если стороны не были должным образом проинформированы о рисках, связанных с такими операциями.

В то же время, реформы 1989 г. в ст. 52 Закона о фондовой бирже Германии, которая связана со ст. 762 и 764 Германского гражданского заключения 1896, предполагалось, что все спекулятивные фьючерсные операции являются недействительными, если только прямо не разрешены немецким законодательством. При этом, что является заслуживающим внимания, такая норма считалась частью общественного порядка [24], а это позволяло судам на ее основании отказывать в реализации договора, который регулируется иностранным правом и заключен за пределами Германии. И хотя сейчас в ряде европейских стран (в частности, в Бельгии, Франции, Нидерландах, Великобритании) законодатели прямо сделали исключение для контрактов, заключаемых на бирже и в которых принимают участие профессиональные инвесторы [23], продолжает существовать угроза, что суд может отказать в иске о принудительном исполнении такой сделки, что является правомерным и по lex causae, и по lex fori, однако неправомерным по закону другого государства, если он приходит к выводу, что тесная связь данной сделки с правом другого государства обусловливает экстерриториальное применение законодательства такой юрисдикции о запрете спекулятивных операций. 
В Чехии, Италии и Испании [25] выбор права может быть также признан недействительным, если он существенным образом несправедлив в отношении одной из сторон сделки, что классифицируется в этих странах как мошенничество. Такое решение может быть принято судом в случае, если одна из сторон, имея веские экономические или другие рычаги влияния, «навязала» другой стороне включения оговорки о применении такого права, которое, не имея прямого отношения к данной операции, не обеспечило надлежащей защиты такой стороны, т.е. речь идет о недобросовестности стороны договора. Так, договоры, заключаемые между профессиональными торговцами ценными бумагами и неинституциональными инвесторами, являются типичным примером ситуации, когда торговец может добиться включения ссылки на право юрисдикции, которая не имеет специальных норм относительно стандартов поведения на рынке ценных бумаг и защиты прав инвесторов. В особенности такой вид мошенничества характерен для Чехии (причем, мошенничеством он выступает относительно других юрисдикций), которая находится на особом счету у FATF ввиду рисков отмывания нелегальных доходов и теневого денежного трафика. Этот нюанс особенно ярко характеризирует тонкость грани и огромные возможности для сращивания мошенничества с ценными бумагами и отмыванием денег.

По мнению экспертов FATF, теневые средства, отмытые через сектор ценных бумаг, могут быть получены как в этом секторе, так и вне его [26]. Для средств, полученных этим сектором, механизмом сокрытия или осложнения выявления источника происхождения являются сделки на рынке ценных бумаг или создания юридических лиц. А относительно противозаконных операций на самом рынке ценных бумаг, - в частности, хищений, инсайдерской торговли, мошенничества с цен- ными бумагами, манипулирование рынком и т.д., - их следствием является получение незаконных средств, которые надо отмыть. В обоих этих случаях сектор ценных бумаг может представлять лицам, отмывающим деньги, двойную пользу: во-первых, они могут отмыть незаконно полученные средства, а, во-вторых, получить дополнительную выгоду от мошеннических операций с ценными бумагами [27].

Так, Италия как член FATF лишь частично регулирует проблемы, с которыми сталкиваются работники ее правоохранительных служб и брокеры, которым приходится работать в условиях потенциальных случаев купли-продажи акций на брокерский кредит с целью отмывания денег. Пытаясь получить быструю прибыль, расчеты по таким сделкам на рынке, где практикуют брокерский кредит, откладывают до последнего момента. Конечно, в таких случаях не пользуются ни трансфертами, ни чеками, поскольку для этого нужно время, а предпочитают наличные. В такой юрисдикции нередко люди переходят из одного банка в другой с деньгами в руках, чтобы не платить банку комиссию за банковский перевод. Если рассчитываются наличными, брокеру трудно установить, кто стоит за этими деньгами. В такой ситуации брокеры часто предполагают, что банки, которые получают наличные, уже выполнили все необходимые шаги для проверки клиентов и раскрыли всю нужную информацию о сделках сомнительного происхождения. Эта разновидность расчета существует на рынках только нескольких стран, среди которых, кроме Италии находится и Чехия.

В Италии и Испании юридическое регулирование сектора ценных бумаг имеет определенные особенности, которые делают его потенциально уязвимым для отмывания грязных денег и мошенничества, а именно:

- процедуры due diligence для проверки клиентов и происхождение их средств 
выполняются не всегда последовательно или выполняются лишь на последнем этапе оформления сделок. Часть профессиональных участников просто предполагают, что такие процедуры уже кто-то выполнил на предыдущих этапах, и поэтому теряют бдительность;

- как и в соглашениях, касающихся других секторов финансовой системы, вопросы собственности и контроля часто скрываются использованием номинальных владельцев, юридических лиц, трастов и др. [28].

В то же время, общее в юридическом урегулировании вопросов квалификации мошенничества с ценными бумагами, обусловленное как работой по гармонизации законодательства стран-членов ЕС, так и требованиями развитого фондового рынка позволяет выделить характерные моменты, отображенные в юрисдикции Германии, Франции, Италии, Испании, Чехии [23, 25, 29-31].

Так, первым безусловным элементом квалификации мошенничества с ценными бумагами является признак материальности. И закон, и судебная практика всех вышеуказанных стран, как и законодательство ЕС, четко указывают, что одного лишь обмана недостаточно. Обман должен быть «материальным», то есть иметь признаки потенциального или фактического материального ущерба для адресата такого обмана. Если попробовать провести условные параллели между европейским и российским уголовным правом, то указание на материальность противоправного поведения, по своей содержательной нагрузке близка к таким понятиям, как «общественная угроза»и «материальный состав преступления». Оба понятия указывают на реальную вредность противоправного поведения для охраняемых в обществе ценностей, определенные негативные последствия.
Учитывая сложность установления признаков материальности мошенничества с ценными бумагами, приведем гипотетический пример. Если корпорация «А» выпускает информационный буклет для потенциальных инвесторов, в котором указаны специально завышенные финансовые прогнозы на следующий год, который объективно является ничем не подкрепленными, то такую информацию, а следовательно, и соединенный с ней обман, следует признавать материальной, поскольку она существенно влияет на процесс принятия решения потенциальными акционерами: покупать акции компании или нет. Материальной будет признаваться даже информация компании о будущем сохранении доходов на уровне показателей прошлого года, даже если при этом были сделаны оговорки о достоверности конкретных цифр [3].

И наоборот, официальное выражение корпорацией оптимистичных прогнозов относительно будущей деятельности, если оно не сочетается с конкретными цифрами, обязательствами или обещаниями, не воспринимается судебной практикой как «материальный» признак обмана. Например, в одном из реальных судебных решений немецкого суда было отмечено, что в рекламных материалах, распространенных среди потенциальных акционеров, содержалось немало предостережений и сообщений о возможных рисках, что делает невозможным обвинения в искажении материальных фактов [4].

В то же время во всех вышеупомянутых юрисдикциях предусмотрено, что не являются манипулированием ценами на фондовом рынке действия, которые имеют целью:

1) поддержание цен на эмиссионные ценные бумаги в связи с их публичным размещением или обращением при условии, что такие действия совершаются участником биржевых торгов на основании соот- 
ветствующего договора с эмитентом таких ценных бумаг;

2) поддержание цен на ценные бумаги открытых или интервальных институтов совместного инвестирования в связи с их выкупом в случаях, установленных законом;

3) поддержание цен, спроса, предложения или объема торгов финансовыми инструментами при условии, что такие действия совершаются участником биржевых торгов на основании соответствующего договора с фондовой биржей.

Также не признаются манипулированием на фондовом рынке действия, совершаемые органами государственной власти в связи с реализацией денежно-кредитной политики или политики управления государственным долгом.

Следующим рассмотрим признак преступного умысла. Сразу следует отметить, что успешное рассмотрение и гражданских, и уголовных дел о злоупотреблениях на фондовом рынке требуют установления признаков вины. Разница заключается только в содержании субъективного отношения правонарушителя и преступника к своим действиям и, соответственно, к их последствиям. Криминальный умысел может быть установлен в том случае, когда действия лица являются целенаправленными и осознанными, а не является результатом ошибки, небрежности или невнимательности.

Обязательным элементом рассматриваемого преступления является совершение противоправных действий «в связи с приобретением или продажей ценной бумаги». Для квалификации противоправных действий как мошенничества с ценными бумагами должна иметь место соответствующая транзакция, то есть приобретение или продажа акций. Итак, корректное определение таких понятий, как «акция», «приобретение» и «продажа», являются фундаментальными для опреде- ления оснований привлечения к уголовной ответственности.

Отношения свободного рынка традиционно характеризуются широкими правами участников в части заключения соглашений об инвестировании или, наоборот, привлечения дополнительного капитала. А, следовательно, ценные бумаги, как действенные финансовые инструменты, призванные обслуживать самые разнообразные потребности рынка, должны сами быть разнообразными. И здесь со всей актуальностью возникает следующий вопрос: как правильно установить, является ли определенный финансовый инструмент ценной бумагой?

Опять вынуждены констатировать непоследовательность, и даже противоречивость судебного права в вышеуказанных странах, особенно во Франции, где Высший суд был вынужден признать отсутствие в своих решениях четкого метода анализа финансовых инструментов на предмет их охвата понятием «акция» [28]. Ознакомление с соответствующей категорией гражданских и уголовных дел свидетельствует о существовании трех основных критериев (вопросов) определение ценной бумаги:

1) может на основании закона признаваться ценной бумагой финансовый документ (акция, вексель), который по своей форме соответствует признакам такого, однако не был включен в оборот в качестве инвестиции с целью получения дохода;

2) могут признаваться ценными бумагами финансовые инструменты, урегулированные нормами другого законодательства (не как ценные бумаги);

3) инвестиционная схема, которая не является ценной бумагой по своей форме, может признаваться «инвестиционным контрактом», а значит и ценной бумагой де-юре и де-факто.

Именно вышеуказанные вопросы, будучи общими проблемами для всех упомянутых 
юрисдикций, являются предметом активных дискуссий и судебных разбирательств в настоящее время. Можно прогнозировать, что именно эти вопросы будут иметь соответствующее законодательное выражение в ближайшее время.

Подводя итог краткому анализу основных проблемных аспектов регулирования операций с ценными бумагами с целью выявления и квалификации мошенничества, следует еще раз подчеркнуть, что принципы построения системы правового регулирования оборота ценных бумаг, которая характеризуется существенным присутствием публично-правовых элементов, могут детерминировать склонность судов к применению императивных и «оверимперативних» норм, несмотря на выбор сторонами сделки применимого права при подозрении на действия мошеннического характера. Безусловно, осуществление операций с ценными бумагами на международных рынках капитала связано и с другими нюансами правового характера, которые могут усложнить решения коллизионного вопроса или поставить под сомнение выбор сторонами компетентного правопо- рядка, особенно при подозрении в отмывании незаконных доходов. Учитывая такие моменты при первоначальном планировании и структурировании сделки купли-продажи ценных бумаг, можно обеспечить степень определенности относительно применимого права.

В целом, с нашей точки зрения, существуют три фактора, способствующие росту международной преступности в сфере ценных бумаг, которые затрудняют квалификацию мошенничества:

- глобализация и технический прогресс;

- национальная нестабильность, которая накладывает определенный отпечаток на соблюдение норм права;

- корпоративные правонарушения международных корпораций, вследствие неправильного внутреннего контроля в деятельности финансовых учреждений. В то же время, существуют и общие для всех исследуемых стран проблемы при квалификации мошенничества с ценными бумагами, которые являются первыми в очереди на решение их путем изменения национального и международного законодательства.

\section{Библиография:}

1. Мошенский С.3. Рынок ценных бумаг: трансформационные процессы. - М.: «Экономика», 2012. - 240 с.

2. Редзюк Е.В. Тенденции развития финансово-инвестиционньх отношений в мире // Journal of Economy and enterpreneurship // Журнал «Экономика и предпринимательство». - 2013. - №8 (37). - С. 24-30.

3. Гринберг Р. Г. Контуры глобального мира: обозначая будущее // Экономические и социальные перемены. Факты, тенденции, прогно3. - 2014. - №1 (13). - С. 17-28.

4. Директива 2002/87/ЕС Европейского Парламента и Совета от 16 декабря 2002 о дополнительном надзоре за кредитными учреждениями, страховыми компаниями и инвестиционными фирмами в финансовом конгломерате, которое вносит изменения в Директивы Совета 73/239 / ЕЭС, 79/267 / ЕЭС, 92/49 / ЕЭС, 92/96 / ЕЭС, 93/6 / ЕЭС и 93/22 / ЕЭС, директив Европейского Парламента и Совета 98/78 / ЕЭС и 2000/12 / ЕС.

5. Директива 2006/49 / ЕС Европейского Парламента и Совета от 14 июня 2006 о достаточности основного капитала инвестиционных компаний и кредитных учреждений.

6. Директива Совета 86/635 / ЕЭС от 8 декабря 1986 по годовой и консолидированной отчетности банков и других финансовых учреждений.

7. Директива 2001/65 / ЕС Европейского Парламента и Совета от 27 сентября 2001 о внесении изменений и дополнений в Директивы 78/660 / ЕЭС, 83/349 / ЕЭС и 86/635 / ЕЭС о правилах оценки, применяемых в годовой и консолидированной отчетности отдельных видов компаний, а также банков и других финансовых учреждений. 
8. Директива 2004/39 / ЕС Европейского Парламента и Совета 21 апреля 2004 по рынкам финансовых инструментов, которая вносит изменения в Директиву 85/611 / ЕЭС и Директивы 2000/12 / ЕС Европейского Парламента и Совета, а также прекращает действие Директивы Совета 93 / 22 / ЕЭС 93/22 / ЕЭС.

9. Директива Комиссии 2006/73 / ЕС от 10 августа 2006, имплементирующая Директиву 2004/39 / ЕС Европейского Парламента и Совета относительно организационных требований и рабочих условий для инвестиционных фирм и определенных условий для целей настоящей Директивы.

10. Директива 2003/71 / ЕС Европейского Парламента и Совета от 4 ноября 2003 о проспектах, подлежащих опубликованию в случае открытого предложения ценных бумаг или выставления их на продажу, вносящая изменения в Директиву 2001/34 / ЕС.

11. Директива Европейской Комиссии 2007/14 / ЕС от 8 марта 2007, определяющая детальные правила внедрения отдельных положений Директивы 2004/109 / ЕС о гармонизации требований к прозрачности в отношении информации об эмитентах, чьи ценные бумаги допускаются к торгам на регулируемых рынках.

12. Директива 97/9 / ЕС Европейского Парламента и Совета от 3 марта 1997 о схемах компенсации инвесторам.

13. Директива 2003/6 / ЕС Европейского Парламента и Совета от 28 января 2003 об инсайдерской деятельности и манипулированиях рынком (злоупотреблениях на рынке).

14. Директива Комиссии 2004/72 / ЕС от 29 апреля 2004 о выполнении Директивы 2003/6 / ЕС Европейского Парламента и Совета относительно общепринятых рыночных практик, определение внутренней информации относительно вторичных рынков на потребительские товары, составление списков членов, уведомления операций менеджеров и уведомления подозрительных операций.

15. Директива Комиссии 2003/124 / ЕС от 22 декабря 2003 о выполнении Директивы 2003/6 / ЕС Европейского Парламента и Совета по определению публичного разглашения внутренней информации и определения манипуляции на рынке.

16. Директива Комиссии 2003/125 / ЕС от 22 декабря 2003 о выполнении Директивы 2003/6 / ЕС Европейского Парламента и Совета относительно справедливого представления инвестиционных рекомендаций и разглашения конфликта интересов.

17. Директива 2009 / 65 / ЕС Европейского Парламента и Совета от 13 июля 2009 о согласовании законов, подзаконных и административных положений, касающихся институтов совместного инвестирования в ценные бумаги, находящиеся в обращении (UCITS) (пересмотренная версия).

18. Директива Комиссии 2007/16 / ЕС от 19 марта 2007, вводящая Директиву Совета 85/611/ЕС по согласованию законов, подзаконных и административных положений, касающихся институтов совместного инвестирования в ценные бумаги, находящиеся в обращении (UCITS) относительно уточнения некоторых определений.

19. Директива 2002/47 / ЕС Европейского Парламента и Совета от 6 июня 2002 о механизмах применения финансового залога.

20. Директива 98/26 / ЕС Европейского Парламента и Совета от 19 мая 1998 об окончательном расчете в платежных системах и системах расчетов по ценным бумагам.

21. Директива 2007/44/ ЕС Европейского Парламента и Совета от 5 сентября 2007, вносящая изменения и дополнения к Директиве Комиссии 92/49/ЕЭС и Директивам 2002/83/ЕС и 2004/39/EC, 2005/68/ ЕС и 2 006/48/ЕС относительно процедурных норм и критериев оценки для пруденциальной оценки поглощений и увеличения холдингов в финансовом секторе.

22. Rabel E. The Conflict of Laws: A Comparative Study, 2-nd edn. - Ann Arbor: University of Michigan Law School, 1999-2004.

23. Schuster G. Securities Transactions On or Off-Exchange / The Law of Cross-Border Securities Transactions, by H. van Houtte (ed.). - London: Sweet \& Maxwell, 2009. - P. 73-100.

24. Wood P.R. Set-off and Netting, Derivatives, Clearing Systems, 2-nd edn. - London: Sweet \& Maxwell, 2012. $-376 \mathrm{p}$.

25. Guide to capital markets in Europe [Электронный ресурс]. - Режим доступа: https://www.slaughterandmay. com/media/844122/guide-to-capital-markets-in-europe.pdf 
DOI: $10.7256 / 2226-6305.2016 .2 .17239$

При цитировании этой статьи сноска на doi обязательна

Международное право и международные организации•2•2016

International Law and International Organizations

26. Rome Convention on the Law Applicable to Contractual Obligations, opened for signature in Rome on 19 June 1980 г. (80/934 / EEC) // Official Journal. L266.

27. FATF Standards Issue [Электронный ресурс] // Режим доступа: http://www.fatf-gafl.organiization/ FATFDocs_en.htm\#Trends

28. Global Market Abuse News - Spring 2015 [Электронный ресурc]. - Режим доступа: http://www.lexology. com/library/detail.aspx?g=108cf1b9-4c66-45ba-a6e8-64b2b9f2a2af

29. Corporate crime, fraud and investigations in Germany: overview [Электронный ресурс]. - Режим доступа: http://uk.practicallaw.com/6-554-9114

30. Corporate crime, fraud and investigations in France: overview [Электронный ресурс]. - Режим доступа: http://uk.practicallaw.com/2-519-9872?source=relatedcontent

31. Corporate crime, fraud and investigations in Italy: overview [Электронный ресурс]. - Режим доступа: http://uk.practicallaw.com/1-520-8645? source=relatedcontent

\section{References (transliterated):}

1. Moshenskii S.Z. Rynok tsennykh bumag: transformatsionnye protsessy. - M.: «Ekonomika», 2012. - $240 \mathrm{~s}$.

2. Redzyuk E.V. Tendentsii razvitiya finansovo-investitsionn'kh otnoshenii v mire // Journal of Economy and enterpreneurship // Zhurnal «Ekonomika i predprinimatel'stvo». - 2013. - №8 (37). - S. 24-30.

3. Grinberg R. G. Kontury global'nogo mira: oboznachaya budushchee // Ekonomicheskie i sotsial'nye peremeny. Fakty, tendentsii, prognoz. - 2014. - №1 (13). - S. 17-28.

4. Rabel E. The Conflict of Laws: A Comparative Study, 2-nd edn. - Ann Arbor: University of Michigan Law School, 1999-2004.

5. Schuster G. Securities Transactions On or Off-Exchange / The Law of Cross-Border Securities Transactions, by H. van Houtte (ed.). - London: Sweet \& Maxwell, 2009. - P. 73-100.

6. Wood P.R. Set-off and Netting, Derivatives, Clearing Systems, 2-nd edn. - London: Sweet \& Maxwell, 2012. $-376 \mathrm{p}$. 